\title{
Kinetics of Dissolution of Copper in Liquid Tin With Ultrasonic Waves
}

\author{
Xuemin Sun ${ }^{a}(\mathbb{D})$, Weiyuan Yu ${ }^{a, *}$, Baolei Wu ${ }^{a}$, Guoqing Yang ${ }^{a}$ \\ ${ }^{a}$ Lanzhou University of Technology, State Key Laboratory of Gansu Province, Advanced Processing and \\ Recycling of Nonferrous Metals, Lanzhou 730050, Gansu Province, PR China
}

Received: June 20, 2019; Revised: November 29, 2019; Accepted: March 06, 2020

\begin{abstract}
Ultrasonic-assisted soldering, as a type of new welding method, is widely used in the field of electronic packaging. This research used the immersion method to study the dissolution behavior of copper in liquid tin and the growth of IMC at 513, 543, and $573 \mathrm{~K}$ with/without ultrasonic waves. The amount of copper dissolved and IMC layer thickness were measured and the dissolution activation energy of $\mathrm{Cu} / \mathrm{Sn}$ was calculated. Experimental results indicated that Without ultrasonic waves, the amount of copper dissolved increased nonlinearly with immersion time. However, with ultrasonic waves, the amount of copper dissolved increased linearly with immersion time. The amount of copper dissolved in liquid tin increased considerably with ultrasonic waves, and the dissolution rate increased by 7-8 times. The thickness of the IMC layer decreased as the ultrasonic time and ultrasonic power increased. Meanwhile, the ultrasonic waves reduced the dissolution activation energy of the $\mathrm{Sn} / \mathrm{Cu}$ system.
\end{abstract}

Keywords:Ultrasonic wave, Dissolution rate, Activation energy, Ultrasonic power.

\section{Introduction}

As a key process in the electronic packaging industry, soldering is expected to meet new demands with the development of integrated circuits in the sub-micrometer and deep sub-micrometer range. However, some obvious problems need to be resolved, such as strength and reliability of the soldering joint. To solve this problem, several new soldering techniques have received attention. As one of these methods, ultrasonic-assisted soldering has been widely used for electronic packaging. Compared to the traditional soldering method, ultrasonic-assisted soldering can promote the wetting of solder on the substrate ${ }^{1,2}$, remove the oxide film on the surface of the substrate to avoid the problem of residual corrosion of the joint interface flux, and refine grains to improve the shear strength of the solder joint $^{3-5}$. It is suitable for the connection of complex shapes and structures. Most studies have reported that ultrasonic solder bonding can complete the soldering of chips at low temperature within a very short bonding time $e^{6,7}$. However, ultrasonic waves severely corrode the substrate, which has an adverse effect on the reliability of the solder joint. Kannojia et al. ${ }^{8}$ reported Void Formation and Intermetallic Growth in Pulse Electrodeposited Cu-Sn Layers for MEMS Packaging. Li et al. ${ }^{9}$ studied the ultrasonic-assisted soldering of copper and tin at room temperature, and found that ultrasonic cavitation caused the dissolution of a large amount of copper in tin. Chen et al. ${ }^{10}$ studied the ultrasonic-assisted soldering of Ti-6Al-4V and Al-Si. Some deep erosion pits with a diameter of 2-20 $\mu \mathrm{m}$ were formed on the surface of the titanium substrate after ultrasonic waves application. Liu et al. ${ }^{11}$ studied the dissolution behavior of non-reactive systems with ultrasonic vibrations and found that ultrasonic

*e-mail: weiyuanyu2018@163.com. vibrations accelerate the dissolution of $\mathrm{Al}$ in molten $\mathrm{Sn}$. However, for the reaction system, there is relatively scarce literature on the study of dissolution behavior with applied ultrasonic waves. Therefore, it is necessary to study the dissolution behavior in the reaction system with ultrasonic waves.

Copper and tin are the most commonly used materials in the electronics industry. Therefore, in this study, kinetics of dissolution of copper in liquid tin with ultrasonic waves was studied and its mechanism was analyzed. The research results have significance in guiding the application of ultrasonic-assisted soldering in the electronic packaging industry.

\section{Experimental Materials and Methods}

Pure tin particles (99.99\% pure) and pure copper wires $(99.99 \%$ pure) with a diameter of $1 \mathrm{~mm}$ and length $50 \mathrm{~mm}$, respectively, were used in this research. Before the experiment, to remove the surface oxide film, the copper wires were cleaned ultrasonically for $5 \mathrm{~min}$, and then put in a $10 \mathrm{vol} \%$ hydrochloric acid alcohol solution for $3 \mathrm{~min}$, rinsed in water, and dried. Pure tin samples weighing $50 \mathrm{~g}$ were placed in a graphite crucible (40(height) $\times 40 \mathrm{~mm}$ (diameter)), and then was heated to 513,543 , and $573 \mathrm{~K}$ in a controlled-temperature resistance furnace. A K-type thermocouple was inserted into the solder bath to monitor the solder bath temperature. The maximum deviation of bath temperature between prediction and experimental testing was controlled to less than $\pm 2 \mathrm{~K}$. When the solder bath temperature reached the experiment temperature, the copper wires were inserted vertically into the solder bath up to $20 \mathrm{~mm}$. A titanium alloy ultrasonic horn having a diameter of $10 \mathrm{~mm}$, ultrasonic frequency of $28 \mathrm{kHz}$, and ultrasonic 
power range of 300-700 W was inserted vertically into the solder bath up to $18 \mathrm{~mm}$. The distance between the horn and the copper wire was $1 \mathrm{~mm}$. The schematic diagram of the experimental setup is shown in Figure 1.

The immersion times of copper wires in the liquid tin were $10,20,30$, and $40 \mathrm{~s}$ with the action of ultrasonic waves and 20,40,60, and $80 \mathrm{~s}$ without the action of ultrasonic waves. After experiment, the copper wire was quickly removed from the solder bath and quenched in water. In order to reduce experimental errors. Each experiment need to change liquid Tin to ensure liquid Tin is fresh. each experimental parameter was measured three times, and the final dissolution thickness was taken as the average value. In this experiment, to study the effect of ultrasonic power on copper dissolution, the experiment temperature was set to $573 \mathrm{~K}$ for an immersion time of $10 \mathrm{~s}$ under the action

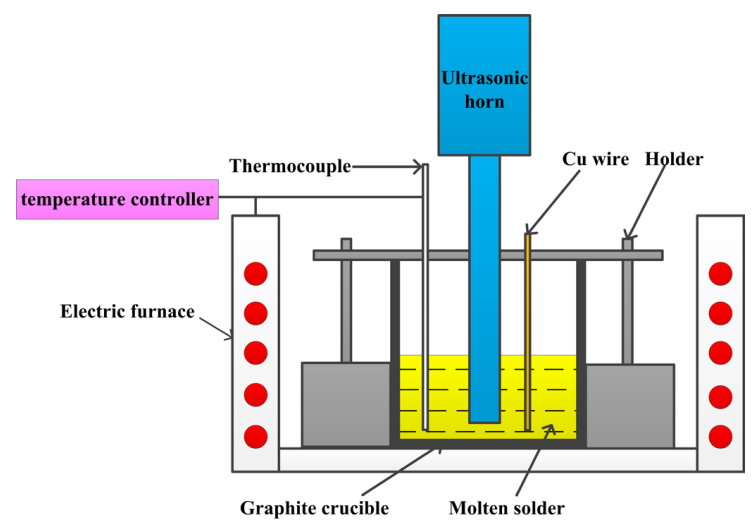

Figure 1. Schematic diagram of the experimental apparatus. of different ultrasonic powers of 300, 500, and $700 \mathrm{~W}$, respectively. At the end of the experiment, residual copper wire was inlaid with epoxy resin and then mechanically polished along the cross section. Observation and analysis of the cross-sectional microstructure was carried out optical microscopy Scope.A1(ZEISS,Germany) and electron microscopy Quanta FEG450(FEI,USA) equipped with an energy spectrometer (EDS). Image Pro Plus software was used to measure the residual area of the copper wire from the images, as shown in Figure 2. The dissolution thickness of the copper wire is defined by the following equation:

$$
D=2\left(\frac{S}{\pi}\right)^{1 / 2}
$$

where $\mathrm{S}$ is the residual area. The dissolution thickness of copper wire is defined as the difference between the radius before and after dissolution. As following equation:

$$
\Delta R=\frac{D_{0}-D}{2}
$$

where $\Delta \mathrm{R}$ is the copper wire dissolution thickness, $D_{0}$ is the diameter of the copper wire before dissolution, and $D$ is the diameter of the copper wire after dissolution.

\section{Experiment Results}

Figure 3 shows the relation curve between the amount of copper dissolved in liquid tin and the ultrasonic action time when the experimental temperature is 513,543 , and $573 \mathrm{~K}$. The data points in the figure were measured experimentally and the curves were fitting. The figures show that the

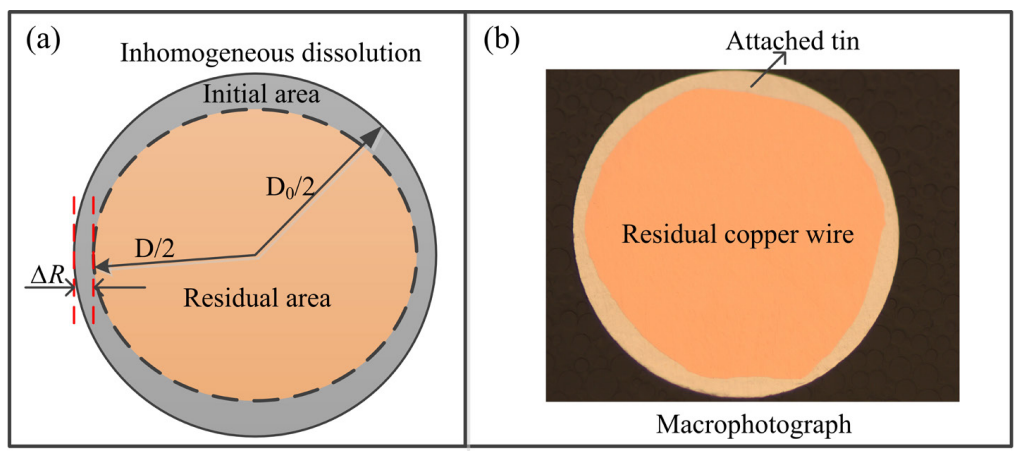

Figure 2. Schematic diagram of the measured area for inhomogeneous dissolution of copper wires.
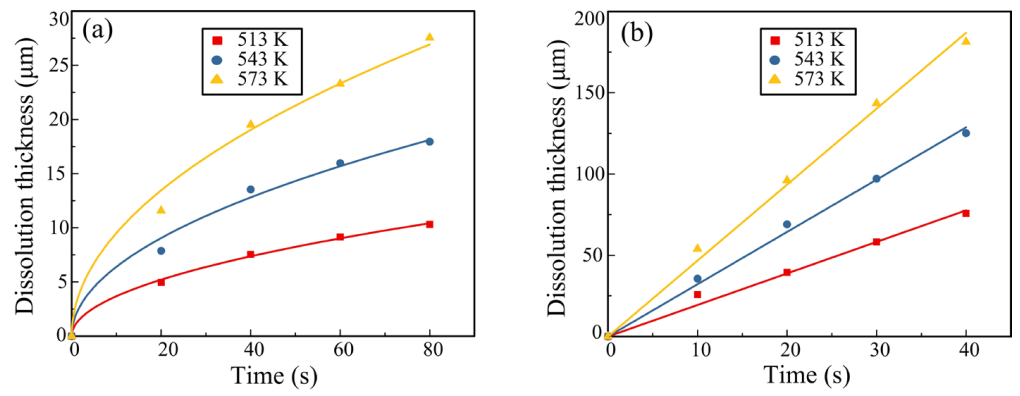

Figure 3. Dissolution thickness of copper in liquid tin (a) vs. immersion time and (b) vs. the square root of immersion time at different temperatures without ultrasonic waves. 
Table 1. Summary of dissolution rate of copper in liquid tin at different temperatures.

\begin{tabular}{|c|c|c|}
\hline $\begin{array}{c}\text { Temperature } \\
\text { (K) }\end{array}$ & $\begin{array}{c}\text { Maximum dissolution } \\
\text { rate without ultrasound } \\
(\mu \mathrm{m} / \mathrm{s})\end{array}$ & $\begin{array}{l}\text { Dissolution rate } \\
\text { with ultrasound } \\
\quad(\mu \mathrm{m} / \mathrm{s})\end{array}$ \\
\hline 513 & 0.25 & 1.94 \\
\hline 543 & 0.39 & 3.22 \\
\hline 573 & 0.58 & 4.67 \\
\hline
\end{tabular}

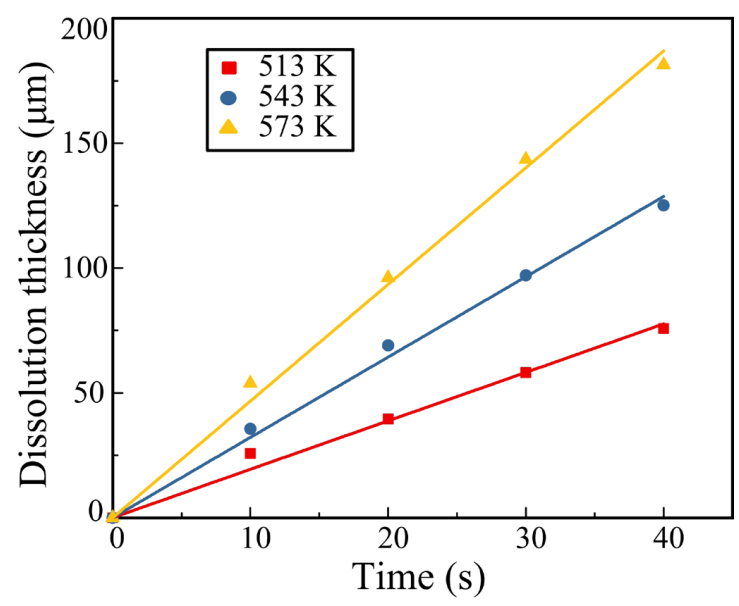

Figure 4. Dissolution thickness of copper in liquid tin vs. immersion time at different temperatures with ultrasonic waves.

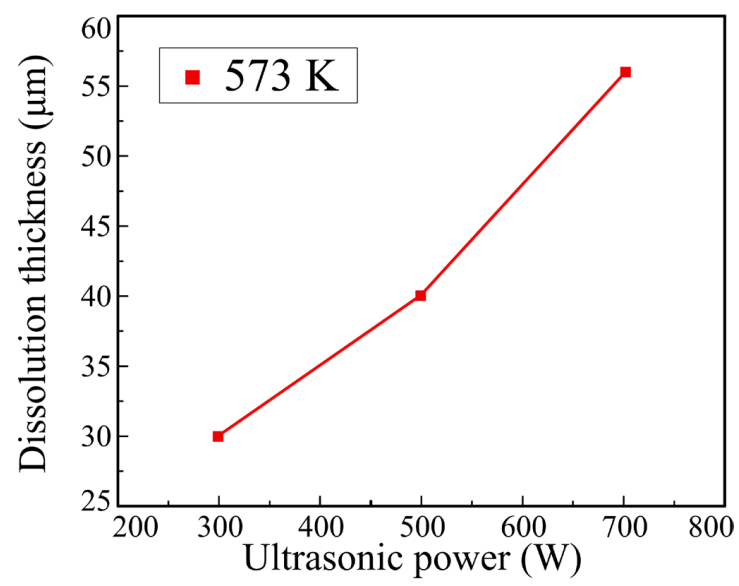

Figure 5. Relation between dissolution thickness of copper in liquid tin and ultrasonic power with ultrasonic waves. dissolution thickness of copper in liquid tin increases with rising experimental temperature and with increase in immersion time. It is seen that the change in dissolution is nonlinear with increase in immersion time. The dissolution rate is fast at the initial stage, and gradually slows down as the immersion time increases The dissolution thickness was proportional to the square root of the immersion time, as shown in Figure 3(b). However, when the ultrasonic wave was applied, the dissolution thickness increased linearly with the immersion time, as shown in Figure 4.

That is, the dissolution occurs at constant speed. The maximum dissolution rate of copper in liquid tin with and without ultrasonic waves was calculated. The results are given in Table 1.

The dissolution rate of copper in liquid tin with ultrasound action was approximately 7-8 times higher than that of the maximum dissolution rate without the ultrasound action. Figure 5 shows the relationship between the dissolution thickness and the ultrasonic power. It is found that the dissolution thickness increases with the increases of the ultrasonic power.

Figure 6 shows the BSE images of the cross-section after dissolution of copper without ultrasound waves at $573 \mathrm{~K}$. A light grey scallop-like intermetallic compound layer is formed between the interface of copper and the solder, which is $\mathrm{Cu}_{6} \mathrm{Sn}_{5}$ by EDS analysis. The thickness of $\mathrm{Cu}_{6} \mathrm{Sn}_{5}$ layer at different immersion times at $573 \mathrm{~K}$ was shown in Figure 7. The results show that the thickness of the $\mathrm{Cu}_{6} \mathrm{Sn}_{5}$ layer increases from $1.26 \mu \mathrm{m}$ at $40 \mathrm{~s}$ to $1.75 \mu \mathrm{m}$ at $80 \mathrm{~s}$.

Figure 8 shows that the BSE images of the cross-section after dissolution of copper with ultrasonic waves at $573 \mathrm{~K}$. It is found that there are broken $\mathrm{Cu}_{6} \mathrm{Sn}_{5}$ particles at the interface. The thickness of $\mathrm{Cu}_{6} \mathrm{Sn}_{5}$ layer for different ultrasonic power and ultrasonic times at $573 \mathrm{~K}$ was shown in Figure 9. The results show that the thickness of the $\mathrm{Cu}_{6} \mathrm{Sn}_{5}$ layer decreases with the increase of ultrasonic power and ultrasonic time. The thickness of the $\mathrm{Cu}_{6} \mathrm{Sn}_{5}$ layer is reduce from $1.32 \mu \mathrm{m}$ at $10 \mathrm{~s}$ to $1.08 \mu \mathrm{m}$ at $40 \mathrm{~s}$ with ultrasonic power $700 \mathrm{~W}$.

\section{Discussion}

The dissolution rate of the copper matrix in liquid tin is usually expressed by the following equation ${ }^{12-14}$ :

$$
d C / d t=K\left(\frac{A}{V}\right)\left(C_{S}-C\right)
$$
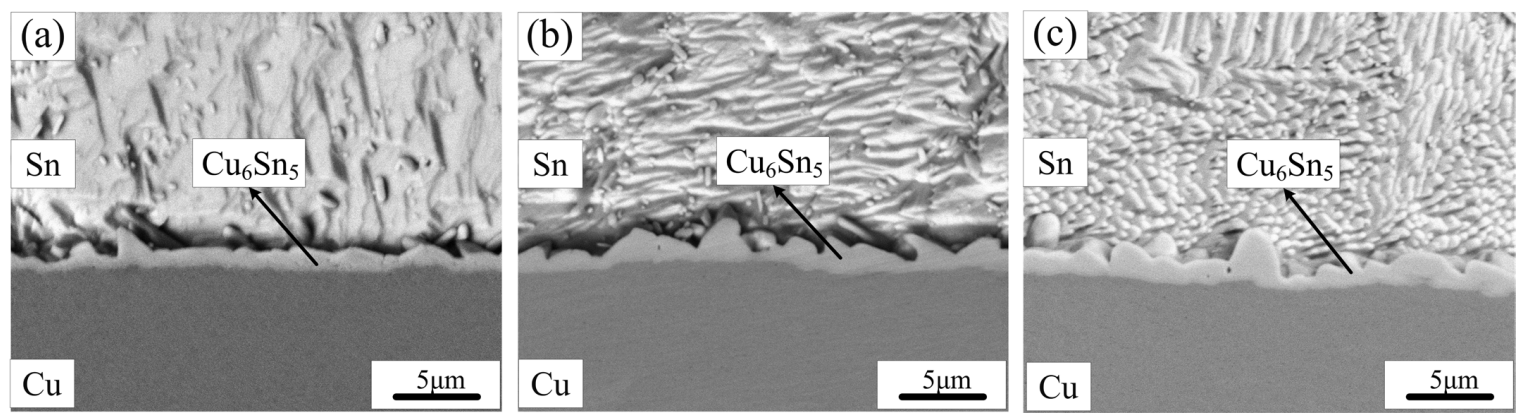

Figure 6. Cross-sectional BSE images after dissolution at $573 \mathrm{~K}$ for different imersion time without ultrasound waves: (a) $40 \mathrm{~s}$; (b) $60 \mathrm{~s}$; (c) $80 \mathrm{~s}$. 
where $C$ is the concentration of copper in liquid tin after immersion time t, $K$ is a dissolution rate constant, $A$ is the interface area between copper and liquid tin, $V$ is the volume of liquid tin, and $C_{s}$ is the saturation concentration of

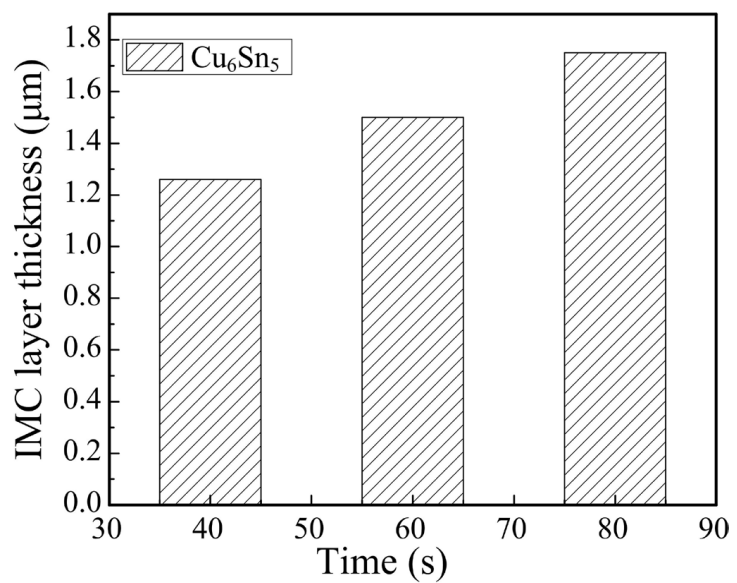

Figure 7. The thickness of $\mathrm{Cu}_{6} \mathrm{Sn}_{5}$ layer at $573 \mathrm{~K}$ for different imersion time.
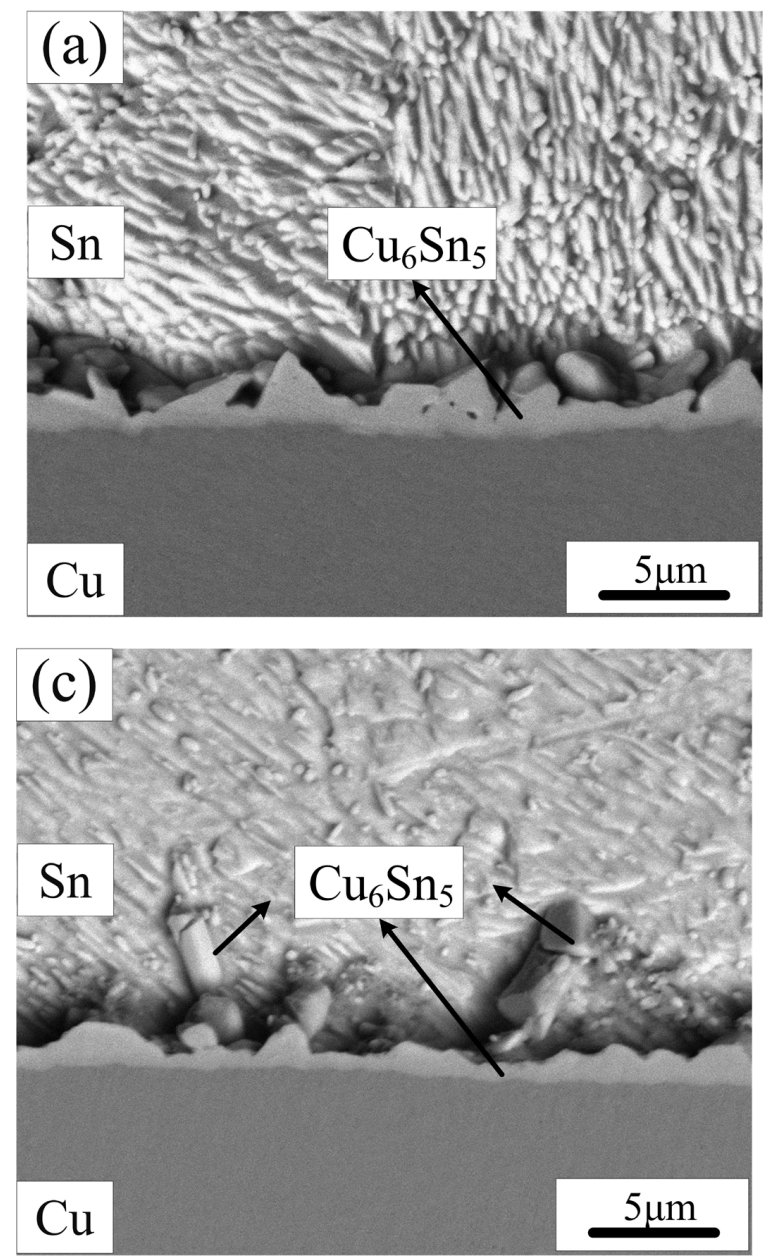

copper in liquid tin. In this study, the values of $A$ and $V$ were constant in different experiments. According to formula 3, $(C s-C)$ is the driving force behind the dissolution of copper in liquid tin, and the dissolution rate is augmented with the increase in the $(C s-C)$ value. According to the $\mathrm{Cu}-\mathrm{Sn}$ binary phase diagram, the saturation solubility of copper in tin and the diffusion rate of elements increases with increasing temperature. Therefore, the dissolution rate is accelerated with the increase in $(C s-C)$. The figures show an incremental increase in dissolution as the temperature increases.

In this study, when the copper wire was inserted into liquid tin, on the one hand, the copper atom was directly dissolved into liquid tin, and on the other hand, an IMC layer was formed on the surface of the copper substrate. Therefore, the amount of copper wire dissolved was a result of competition for the dissolution of copper and the growth of interfacial intermetallic compound ${ }^{15}$. When no ultrasonic waves were applied, at the beginning of dissolution, interface copper atoms and tin atoms diffused easily because the thickness of the interface IMCs layer was lower. This resulted in a higher dissolution rate and a faster growth rate of the IMC layer. However, the IMC layer, which hindered the diffusion of copper atoms and tin atoms, became increasingly thicker
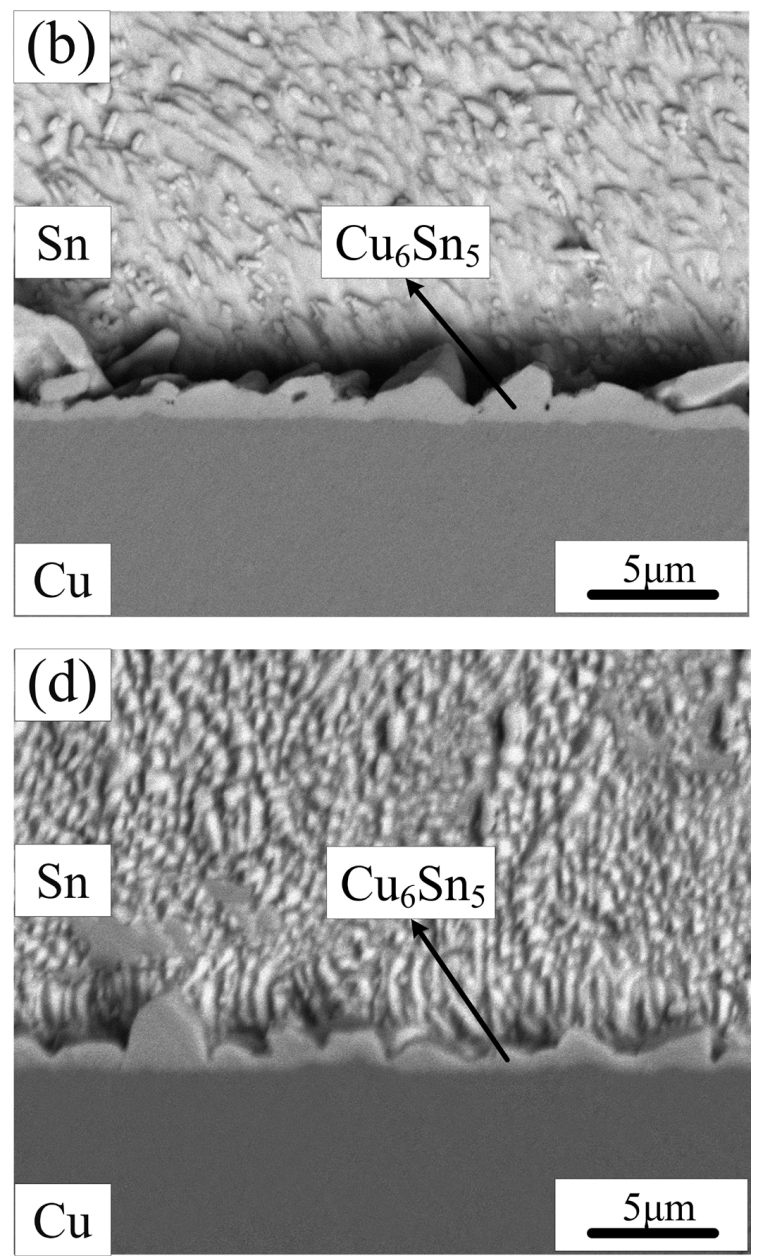

Figure 8. Cross-sectional BSE images after dissolution at $573 \mathrm{~K}$ with ultrasound waves:(a) $500 \mathrm{~W} ; 10 \mathrm{~s}$;(b) $700 \mathrm{~W} ; 10 \mathrm{~s}$;(c) $700 \mathrm{~W}-20 \mathrm{~s}$; (d) $700 \mathrm{~W} ; 40 \mathrm{~s}$. 
(Figure 6a-c) as the immersion time increased, eventually resulting in the retardation of the dissolution rate. Figure $3 \mathrm{a}$ shows that dissolution thickness vs immersion time is a parabolic dependence and Figure $3 \mathrm{~b}$ shows that dissolution thickness vs. $\mathrm{t}^{1 / 2}$ is linear, corresponding to the model in which the dissolution process was diffusion-controlled ${ }^{10}$. The diffusion-controlled dissolution of the control samples was attributed to the concentration gradient of copper.

When ultrasonic waves were applied on the liquid solder, strong acoustic eddy currents and cavitation were generated in the liquid solder. This resulted in the acceleration of the transfer rate of interfacial substances ${ }^{16,17}$, so that the dissolved copper atoms could be rapidly distributed throughout the tin solution. This was because the amount of liquid tin was sufficient, and copper atoms could be infinitely solid dissolved in Sn liquid. The change of copper wire before and after dissolution was shown in Figure 10, and the varied of liquid tin before and after dissolution was shown in Figure 11. Therefore, with ultrasonic agitation, a high concentration of copper atoms at the $\mathrm{Sn} / \mathrm{Cu}$ interface was transferred into liquid tin, and $(C s-C)$ was always kept at the maximum level. On the other hand, the interface IMC layer became

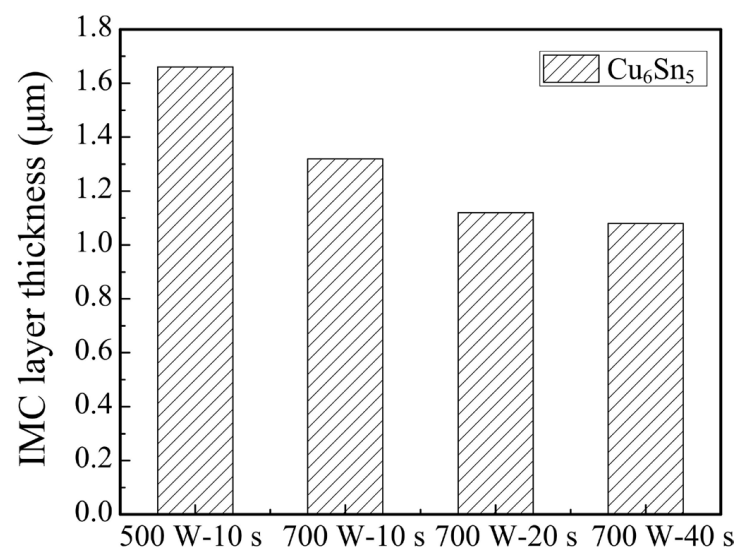

Figure 9. The thickness of $\mathrm{Cu}_{6} \mathrm{Sn}_{5}$ layer at $573 \mathrm{~K}$ with ultrasound waves.

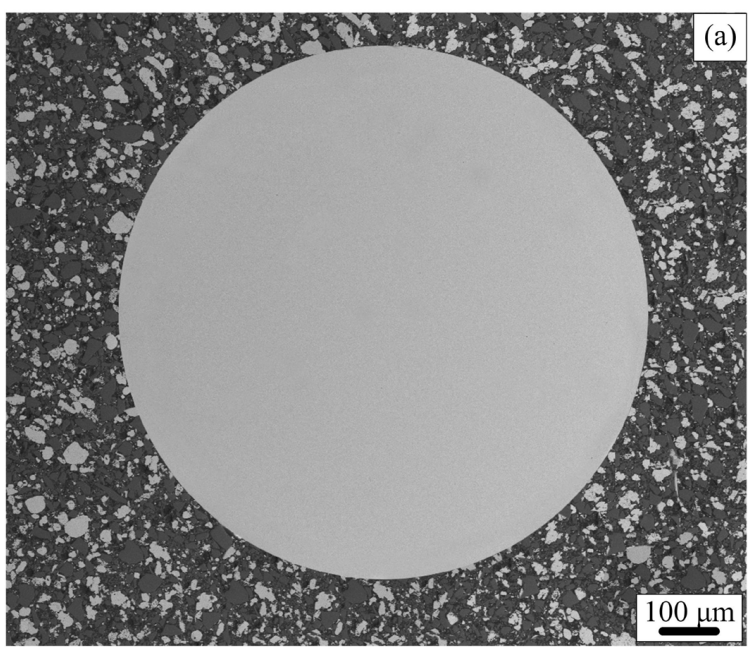

thinner with ultrasonic crushing ${ }^{18,19}$ (as shown in Figure 8b-d), resulting in the diffusion path of copper atoms to the liquid tin becoming shorter, the amount of copper atoms diffused per unit time increasing, and the amount of copper wire dissolved increasing. According to the above analysis results and the experimental results of the dissolution curve (as shown in Figure 4), it could be inferred that the dissolution process for copper in liquid tin had reaction rate-controlled kinetics and diffusion-controlled under application of ultrasonic waves. Santos et al. ${ }^{20}$ found that the higher the ultrasonic power, the higher was the ultrasonic flow and cavitation density. Ji et al. ${ }^{21}$ found that the IMCs grain size and thickness of the boned joint decreased with increased ultrasonic power. The above research showed that the higher the ultrasonic power, the more intense was the effect of ultrasonic waves. This conclusion is consistent with the experimental results of this study. The dissolution rate of copper in liquid tin was accelerated (Figure 5) and the interface IMC layer was thinned (Figure 8a and b) with increase in ultrasonic power.

The dissolution kinetics of copper can be expressed by the following formula ${ }^{22}$ :

$$
X(T, t)=D t^{n}
$$

where $X$ is the thickness of copper wire, $T$ is the temperature of liquid tin, $t$ is the dissolution time, and $D$ is the diffusion coefficient.

The relationship between the diffusion coefficient $D$ and temperature can be expressed by the Arrhenius equation:

$$
D=D_{0} e^{\frac{-Q}{R T}}
$$

where $D_{0}$ is the pre-factor, $Q$ is the activation energy of copper dissolved in the tin solution, and $R$ is the gas constant.

The experimental results with and without ultrasonic waves were fitted according to formula 4 , and the values of $D$ at different temperatures could be obtained. Then the Arrhenius curves were drawn according to formula 5, as shown in Figure 12.

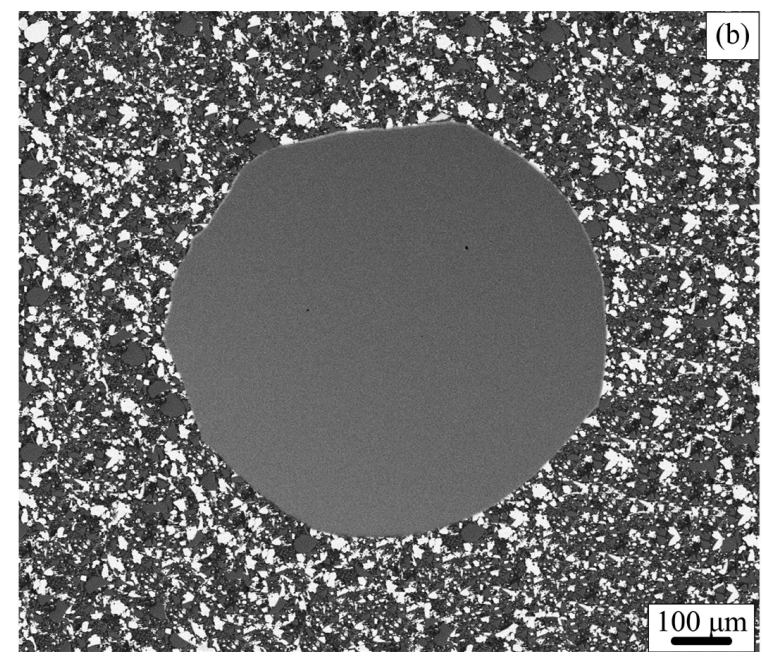

Figure 10. The micrographs of copper wires: (a) before dissolution; (b) after dissolution. 


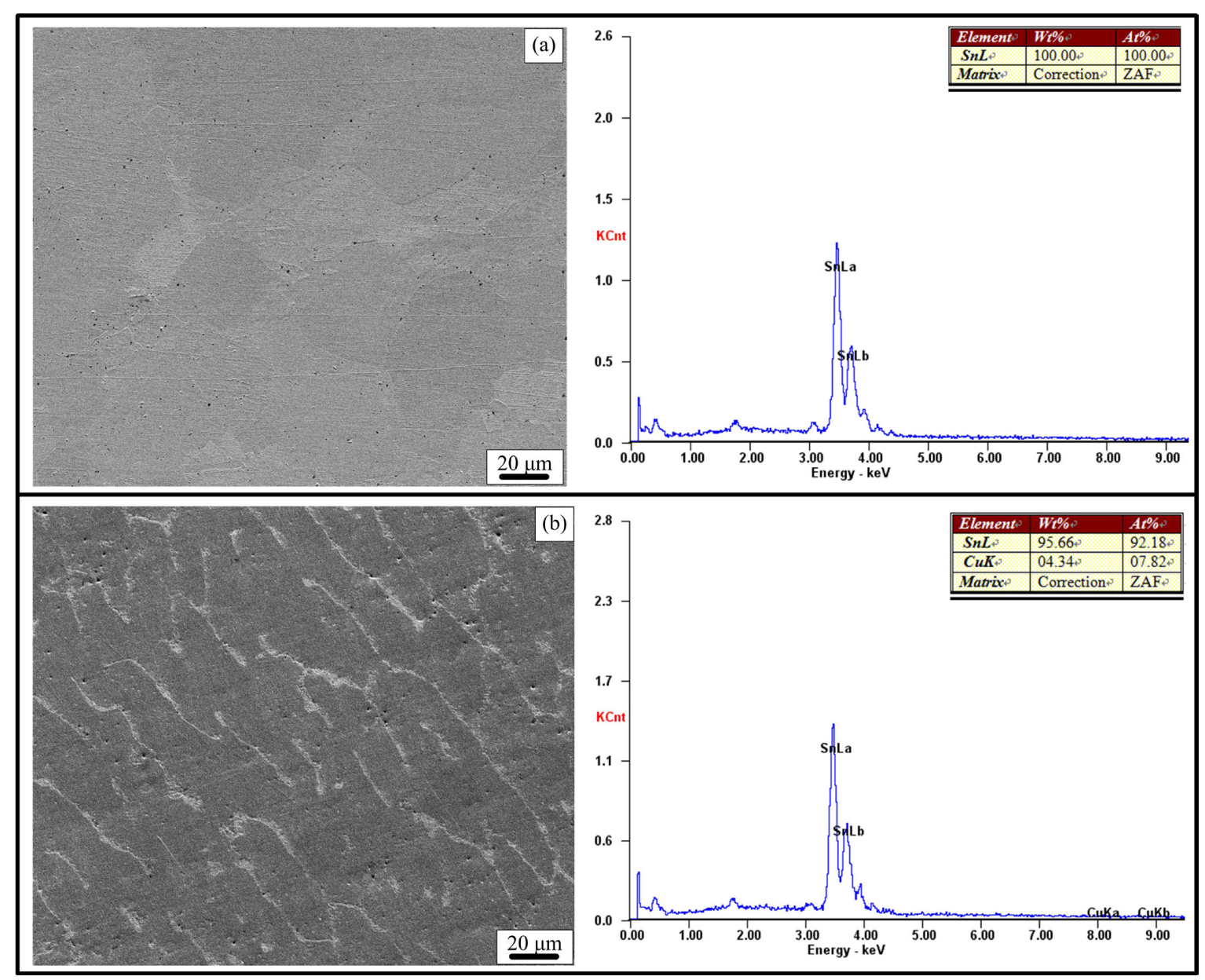

Figure 11. The microstructure and copper content of liquid tin: (a) before dissolution; (b) after dissolution.

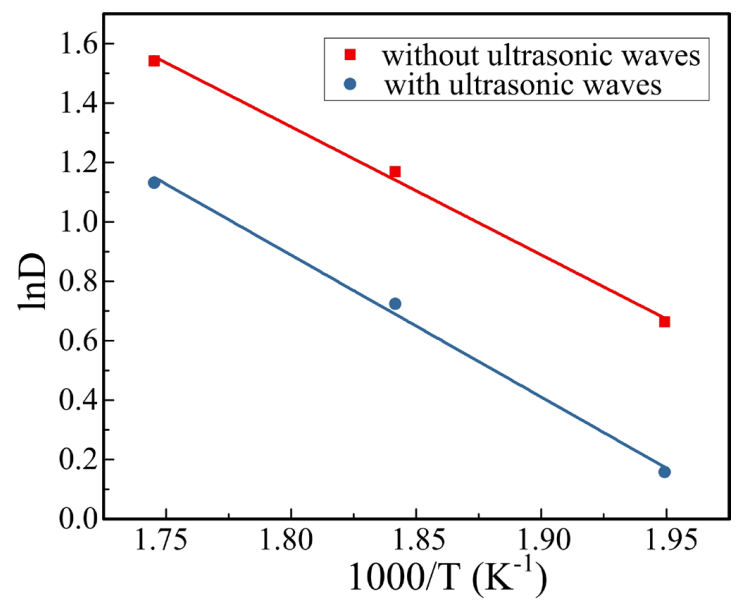

Figure 12. Arrhenius plots of the dissolution rate of pure $\mathrm{Cu}$ in pure Sn with and without applied ultrasonic waves.

Figure 12 shows the Arrhenius plots for the dissolution rate of copper in liquid tin with ultrasonic waves, along with the data for the case without ultrasonic waves. The plots exhibit good linearity. Therefore, we could calculate the apparent activation energies for the dissolution of copper into liquid tin. The values are $35.83 \mathrm{~kJ} / \mathrm{mol}$ with ultrasonic waves and $39.74 \mathrm{~kJ} / \mathrm{mol}$ without ultrasonic waves. We found that the application of ultrasonic waves reduced the dissolution activation energy of the $\mathrm{Sn} / \mathrm{Cu}$ system. This is mainly due to the oxide film on the surface of copper was broken with ultrasonic waves making the dissolution and reaction of copper and tin became easily. The required energy of dissolution reduced, so the dissolution activation energy of the $\mathrm{Sn} / \mathrm{Cu}$ system reduced. In this study, the dissolution activation energy of pure copper in pure tin without ultrasonic waves was greater than that reported in the literature ${ }^{23}$, which may be caused by the incomplete cleaning of the copper surface oxide film.

It can be seen from the above analysis that the dissolution behavior of copper wire after ultrasonic treatment is different from that without ultrasonic treatment. First of all, the thermal effect of cavitation caused by ultrasound can make the temperature of the interface micro region increase rapidly, which makes the $C_{S}$ near the interface increase, and aggravates the dissolution process; Secondly, the diffusion of copper at the interface to the liquid tin will be intensified by ultrasonic sound flow; Thirdly, the oxide film on the surface of copper was broken with ultrasonic waves making the dissolution and reaction of copper and tin became easily. The required energy of dissolution reduced, so the dissolution activation 
energy of the $\mathrm{Sn} / \mathrm{Cu}$ system reduced. These factors make the dissolution rate much higher than that without ultrasound.

\section{Conclusion}

The kinetics of dissolution of copper in liquid tin with ultrasonic waves was studied and its mechanism was analyzed.

(1) Ultrasonic waves had a significant effect on the dissolution rate of copper in a tin bath. Compared to no ultrasonic action, the dissolution rate was increased by $7-8$ times. As the ultrasonic time and ultrasonic power were increased, the thickness of the interface IMC layer decreased.

(2) The dissolution activation energy of copper in liquid tin was $35.83 \mathrm{~kJ} / \mathrm{mol}$ with ultrasonic waves and $39.74 \mathrm{~kJ} / \mathrm{mol}$ without ultrasonic waves. Thus, ultrasonic waves reduced the dissolution activation energy of the $\mathrm{Sn} / \mathrm{Cu}$ system.

(3) Without ultrasonic waves, the dissolution of copper in liquid tin was controlled by atomic diffusion; however, with ultrasonic waves, the dissolution of copper in liquid tin was controlled by reaction rate.

\section{Acknowledgment}

The authors gratefully acknowledge the financial support provided by National Natural Science Foundation of China (No. 51465032).

\section{References}

1. Xu ZW, Ma L, Yan JC, Yang SQ, Du SY. Wetting and oxidation during ultrasonic soldering of an alumina reinforced aluminumcopper-magnesium (2024 Al) matrix composite. Composites Part A: Applied Science and Manufacturing. 2012;43(3):407-14.

2. Yu WY, Liu SH, Liu XY, Liu MP, Shi WG. Interface reaction in ultrasonic vibration-assisted brazing of aluminum to graphite using Sn-Ag-Ti solder foil. J Mater Process Technol. 2015;221:285-90.

3. Vianco PT, Hosking FM, Rejent JA. Ultrasonic soldering for structural electronic applications. Welding Journal-Including Welding Research. 1996;75(11):343s.

4. Lanin VL. Ultrasonic soldering in electronics. Ultrason Sonochem. 2001;8:379-85.

5. Wei-Yuan Y, Liu SH, Liu XY, Shao JL, Liu MP. Wetting behavior in ultrasonic vibration-assisted brazing of aluminum to graphite using Sn-Ag-Ti active solder. Surf Rev \& Lett. 2015;22(3):1550035
6. Kim JM, Jung JP, Zhou YN, Kim JY. Ambient temperature ultrasonic bonding of Si-Dice Using Sn-3.5wt.\%Ag. J Electron Mater. 2008;37:324-30.

7. Hong SM, Kang CS, Jung JP. Fluxless Sn-3.5 mass\%Ag solder bump flip chip bonding by ultrasonic wave. Mater Trans. 2002;43:1336-40.

8. Kannojia HK, Sharma SK, Dixit P. Void formation and intermetallic growth in pulse electrodeposited $\mathrm{Cu}-\mathrm{Sn}$ layers for MEMS packaging. J Electron Mater. 2018;47(12):7386-400.

9. $\mathrm{Li}$ M, Li Z, Xiao Y, Wang C. Rapid formation of $\mathrm{Cu} / \mathrm{Cu} 3 \mathrm{Sn} / \mathrm{Cu}$ joints using ultrasonic bonding process at ambient temperature. Appl Phys Lett. 2013;102:094104.

10. Chen X, Yan J, Gao F, Wei J, Xu Z, Fan G. Interaction behaviors at the interface between liquid Al-Si and solid Ti-6Al-4V in ultrasonic-assisted brazing in air. Ultrason Sonochem. 2013;20:144-54.

11. Liu Y, Yu W, Liu Y. Effect of ultrasound on dissolution of Al in Sn. Ultrason Sonochem. 2019;50:67-73.

12. Izuta G, Tanabe T, Suganuma K. Dissolution of copper on Sn-Ag-Cu system lead free solder. Solder Surf Mt Technol. 2007;19:4-11

13. Takemoto T, Takemoto M. Dissolution of stainless steels in molten lead-free solders. Solder Surf Mt Technol. 2006;18:2430 .

14. Takemoto T, Uetani T, Yamazaki M. Dissolution rates of iron plating on soldering iron tips in molten lead-free solders. Solder Surf Mt Technol. 2004;16:9-15.

15. Huang ML, Loeher T, Ostmann A, Reichl H. Role of $\mathrm{Cu}$ in dissolution kinetics of $\mathrm{Cu}$ metallization in molten Sn-based solders. Appl Phys Lett. 2005;86:181908.

16. Valentina B, Shchukin DG, Gorin DA, Alexey K, Helmuth $\mathrm{MH}$. A new approach to nucleation of cavitation bubbles at chemically modified surfaces. Physical Chemistry Chemical Physics Pccp. 2011;13:8015-23.

17. Skorb EV, Shchukin DG, Helmuth MH, Andreeva DV. Ultrasound-driven design of metal surface nanofoams. Nanoscale. 2010;2:722-7.

18. Chen $\mathrm{H}$. Iridescent rings around cavitation erosion pits on surface of mild carbon steel. Wear. 2010;269:602-6.

19. Dular M, Delgosha OC, Petkovšek M. Observations of cavitation erosion pit formation. Ultrason Sonochem. 2013;20:1113-20.

20. H.M. Santos, C. Lodeiro, J. Capelo-Artínez. The power of ultrasound, ultrasound in chemistry. Weinheim: Wiley-VCH Verlag GmbH \& Co. KGaA; 2009. p. 1-16.

21. Ji HJ, Wang Q, Li MY. Microstructural evolution of lead-free solder joints in ultrasonic-assisted soldering. J Electron Mater. 2016;45:88-97.

22. Sharif A, Chan YC. Dissolution kinetics of BGA Sn-Pb and $\mathrm{Sn}-\mathrm{Ag}$ solders with $\mathrm{Cu}$ substrates during reflow. Mater $\mathrm{Sci}$ Eng B. 2004;106:126-31.

23. Faizan M. Dissolution of Copper and formation of IMC in bulk lead-free solders. Mater Manuf Process. 2014;30:169-74. 